\title{
Intoxicação experimental com extratos de Mascagnia rigida (Malpighiaceae) em camundongos
}

[Experimental intoxication in mice with extracts of Mascagnia rigida (Malpighiaceae)]

\author{
M.M. Melo ${ }^{1}$, D. Verçosa Júnior ${ }^{1}$, M.C.L. Pinto ${ }^{1}$, J.B. Silveira ${ }^{1}$, V. Ferraz ${ }^{2}$, R. Ecco ${ }^{1}$, P.R.O.Paes, ${ }^{1}$ \\ ${ }^{1}$ Escola de Veterinária - UFMG \\ Caixa Postal 567 \\ 30123-970 - Belo Horizonte, MG, \\ ${ }^{2}$ Instituto de Ciências Exatas - UFMG - Belo Horizonte, MG
}

\begin{abstract}
RESUMO
Foi realizado o fracionamento químico do extrato aquoso da Mascagnia rigida Griseb., uma importante planta tóxica no Brasil, para se obter cinco substratos ricos em diferentes grupos químicos - alcalóides, flavanóides, taninos, saponinas e açúcares, ácidos orgânicos e aminoácidos -, e investigar a toxicidade dessas frações, exceto a última, em 75 camundongos. Os animais, distribuídos aleatoriamente em cinco grupos, receberam: grupo I - alcalóides; grupo II - flavanóides; grupo III - taninos; grupo IV - saponinas e grupo $\mathrm{V}$ - placebo, este último funcionando como controle negativo. Todos os grupos, com exceção do grupo-controle, redistribuídos em três subgrupos, A, B e C, com cinco animais cada, receberam, respectivamente, $9 \mathrm{~g} / \mathrm{kg}, 18 \mathrm{~g} / \mathrm{kg}$ e $27 \mathrm{~g} / \mathrm{kg}$ de cada substrato. As frações foram fornecidas via oral, diariamente, por sete dias; no sétimo dia, foi coletado sangue para o estudo do perfil sangüíneo e dosagem de enzimas musculares. As frações de alcalóides e taninos foram capazes de causar alteração no perfil enzimático-muscular, com aumento significativo da enzima miocárdica. Observou-se, também, aumento significativo na porcentagem da CK-MB após a administração das frações de saponinas e taninos, comprovando a ação tóxica da $M$. rigida sobre a fibra muscular cardíaca.
\end{abstract}

Palavras-chave: camundongo, Mascagnia rigida, perfil sangüíneo, enzima muscular

\begin{abstract}
A study was carried out to examine the toxic effects of Mascagnia rigida Griseb. Four classes of compounds were extracted from the plant by phytochemistry study and the individual effect of each one on mice was examined as follows: group I-alkaloids; group II-flavones; group III - tannins; group IVsaponins; and group V-water (control). Each group was further divided in three subgroups, A (9g/kg), $B(18 \mathrm{~g} / \mathrm{kg})$, and $C(27 \mathrm{~g} / \mathrm{kg})$, with five mice orally receiving a particular dose, once per day for one week. On the $7^{\text {th }}$ day, blood was collected and hematological exams and levels of muscle enzymes were analyzed. The results showed that both alkaloids and tannins caused a significant increase in myocardial enzyme. Administration of either saponins or tannins fractions caused an increase of CK-MB enzyme. This study showed that Mascagnia rigida Griseb has the ability to cause damage to myocardial fibers.
\end{abstract}

Keywords: mice, Mascagnia rigida, blood profile, muscle enzymes

\section{INTRODUÇ̃̃̃O}

Mascagnia rigida Griseb., planta da família Malpighiaceae conhecida como tingui, vegeta em vários estados brasileiros, especialmente em Minas Gerais. É apontada como uma planta tóxica pertencente ao grupo que causa intoxicação aguda, em que a morte é precedida

Recebido em 17 de abril de 2007

Aceito em 31 de março de 2008

E-mail: marilia@vet.ufmg.br

Apoio: FAPEMIG 
apenas por um curto período de sinais clínicos e, muitas vezes, sem sinais prévios (Melo, 2006).

Quanto ao gênero Mascagnia, sua toxicidade é relatada desde a década de 40. Cobaias experimentalmente intoxicadas com Mascagnia publiflora (via tubo estomacal) apresentaram sinais neurológicos, fraqueza, tremores musculares, saltos, posição de decúbito lateral, prostração, convulsões, paralisia e morte (Rocha e Silva, 1940). Poucos são os trabalhos que relatam os princípios ativos isolados da espécie M. rigida. Tokarnia et al. (1961), ao intoxicarem experimentalmente bovinos com $M$. rigida, relataram que os únicos sinais observados foram diminuição até a perda do apetite e depressão, mas esses não ocorreram em todos os animais que morreram. Os autores também não conseguiram determinar a quantidade da planta necessária para levar a óbito a espécie bovina, pois quantidades muito maiores que aquelas que mataram certos animais não causaram a morte em outros.

Pereira et al. (1996) relataram que as folhas verdes e secas de $M$. rigida são tóxicas para caprinos nas doses de 5, 10, 15 e $20 \mathrm{~g} / \mathrm{kg}$, por alterarem as concentrações séricas dos eletrólitos, principalmente potássio, fósforo e magnésio.

Medeiros et al. (2002) descreveram um surto de intoxicação por $M$. rigida em 40 bovinos no agreste do estado da Paraíba, cujos sintomas foram instabilidade, tremores e morte de 20 animais. A intoxicação foi reproduzida e comprovada em coelhos que apresentaram sinais agudos após a ingestão de $5 \mathrm{~g} / \mathrm{kg} \mathrm{PV}$ de $M$. rigida.

Quanto ao estudo fitoquímico da $M$. rigida, Nascimento e Habermehl (1995) isolaram das folhas um glicosídeo, o nafto- $\gamma$-pirona. Saad et al. (1970), ao estudarem outra espécie de Mascagnia (M. publiflora), relataram a presença de glicosídeos cardioativos quimicamente positivos para açúcares desoxi e para núcleo esteroidal.

Apesar de a $M$. rigida representar um importante problema econômico para a pecuária, pouco se sabe sobre os seus princípios tóxicos e seu modo de ação.
Devido à ausência de trabalhos científicos sobre as diferentes frações químicas presentes na $M$. rigida e ao efeito dessas frações sobre o perfil hematológico e bioquímico sérico, este trabalho teve o objetivo de estudar a $M$. rigida em diferentes doses, utilizando o camundongo como modelo experimental.

\section{MATERIAL E MÉTODOS}

Para obtenção dos extratos, $300 \mathrm{~g}$ de folhas $(5 / 6)$ e frutos (1/6) frescos, colhidos em Belo Horizonte (MG), foram triturados em liqüidificador em um litro de água. Após decantação, o extrato aquoso foi filtrado em papel filtro a vácuo. O volume do sobrenadante, líquido marrom-amarelado transparente $\mathrm{e}$ espumante, foi reduzido por liofilização (volume final $100 \mathrm{ml}$ ). Esse extrato aquoso foi, então, fracionado por partição, ou seja, extração por solvente (Matos, 1988), em cinco substratos ricos em diferentes grupos químicos: saponinas, taninos, alcalóides, flavanóides e açúcares, ácidos orgânicos e aminoácidos.

Em um funil de separação de $500 \mathrm{ml}$, colocaramse $100 \mathrm{ml}$ de extrato aquoso, $10 \mathrm{ml}$ de hidróxido de amônio e 160ml de acetato de etila/éter (3:1). Após agitação vigorosa e repouso, obtiveram-se duas camadas: uma aquosa límpida de $\mathrm{pH} 11$ (CA1) e outra orgânica, leitosa (CO1). CO1 foi lavada duas vezes com $50 \mathrm{ml}$ de uma solução aquosa $10 \%$ de hidróxido de amônio, agrupandoa à CA1. À CO1 foram adicionados $100 \mathrm{ml} \mathrm{de}$ ácido clorídrico $6 \mathrm{~N}$. Após agitação vigorosa e repouso, obtiveram-se uma segunda camada aquosa, límpida de $\mathrm{pH} 1$ (CA2), e outra, orgânica, amarelada (CO2). A camada orgânica $\mathrm{CO} 2$ foi lavada duas vezes com $50 \mathrm{ml}$ de ácido clorídrico $6 \mathrm{~N}$, agrupando-a à $\mathrm{CA} 2$. $\mathrm{O}$ substrato $\mathrm{CO} 2$, rico em saponinas, foi seco em rotavapor e redissolvido em $100 \mathrm{ml}$ de água. À camada aquosa CA2 foram adicionados $100 \mathrm{ml}$ de acetato de etila/éter (3:1) e $10 \mathrm{ml}$ de hidróxido de amônio. Após agitação vigorosa e repouso, obtiveram-se uma terceira camada aquosa, escura, leitosa de pH 10 (CA3) e outra, orgânica $\mathrm{CO} 3$, límpida, que foi desprezada. Adicionaramse, lentamente, $40 \mathrm{~g}$ de hidróxido de sódio à CA3, para precipitar os taninos. Esse precipitado sólido marrom-escuro foi diluído em $100 \mathrm{ml}$ de água e neutralizado com ácido clorídrico. $\mathrm{O}$ sobrenadante de $\mathrm{CA} 3$, rico em alcalóides, foi neutralizado com ácido clorídrico. À camada 
aquosa CA1 foram adicionados $20 \mathrm{ml}$ de ácido clorídrico $6 \mathrm{~N}$ e $100 \mathrm{ml}$ de acetato de etila/éter (3:1). Após agitação vigorosa e repouso, obtiveram-se uma quarta camada aquosa (CA4) de $\mathrm{pH}$ 1, límpida, contendo açúcares, aminoácidos, ácidos orgânicos, e outra, orgânica (CO4), rica em flavanóides.

Todos os substratos foram neutralizados e mantidos na concentração correspondente a $1,44 \mathrm{~g} / \mathrm{ml}$ de $M$. rigida de substrato.

A confirmação da classe química principal em cada substrato foi feita por espectrometria de infravermelho e pelo método de prospecção de constituintes químicos de extratos de plantas (Matos, 1988).

Os extratos foram mantidos refrigerados em frascos de $5 \mathrm{ml}$, em geladeira, entre 2 e $4^{\circ} \mathrm{C}$, e mantidos em temperatura ambiente por 30 minutos antes de serem administrados.

Setenta e cinco fêmeas de camundongo Swiss albino, não isogênicas, com oito semanas de idade e pesos entre 25 e $30 \mathrm{~g}$, distribuídas em cinco grupos $(\mathrm{n}=15$ cada $)$ e três subgrupos $(\mathrm{n}=$ 5 cada), alojadas em gaiolas $(40 \times 45 \times 25 \mathrm{~cm})$, receberam água e ração à vontade e foram submetidas ao controle artificial de ciclos de luminosidade (12 horas de luz x 12 horas de escuro).

Os animais do grupo I receberam alcalóides; os do grupo II, flavanóides; os do III, taninos; os do IV, saponinas; e os do V, placebo. Estes últimos funcionaram como controle. Cada grupo foi redistribuído em três subgrupos. Os camundongos do subgrupo A receberam $9 \mathrm{~g} / \mathrm{kg}$ de cada extrato, os do subgrupo B, $18 \mathrm{~g} / \mathrm{kg}$, e os do subgrupo $\mathrm{C}, 27 \mathrm{~g} / \mathrm{kg}$.

Diariamente, durante sete dias, após jejum hídrico e alimentar de duas horas previamente à administração das frações, os animais receberam pela via orogástrica (gavagem), com o auxílio de uma sonda gástrica rígida, $0,4 \mathrm{ml}$ dos extratos. A administração diária de $0,4 \mathrm{ml}$ de cada diluição garantiu a cada indivíduo as dosagens médias descritas.

No sétimo dia de tratamento, após anestesia com solução de $50 \mathrm{mg} / \mathrm{kg}$ de cloridrato de xilazina e $50 \mathrm{mg} / \mathrm{kg}$ de cloridrato de cetamina por via intramuscular, coletou-se $0,3 \mathrm{ml}$ de sangue, no espaço retroorbital, com o auxílio de um tubo de microhematócrito, segundo Verçosa Júnior (2006). As amostras foram acondicionadas em tubos plásticos contendo $50 \mu 1$ de solução de ácido etilenodiamino tetra acético (EDTA) ${ }^{1}$ a $10 \%$ para realização do eritrograma, determinação das concentrações de leucócitos totais e de plaquetas, em aparelho de contagem eletrônica veterinário ${ }^{2}$ (Cunha et al., 2008), confecção de esfregaços sangüíneos, que foram fixados em solução May-Grunwald ${ }^{3}$ e corados em solução Giemsa ${ }^{3}$ para contagem diferencial de leucócitos, segundo Ferreira Neto et al. (1978), e cálculo dos índices hematimétricos (Godoy et al., 2007).

Com a coleta de sangue para as avaliações hematológicas, colheu-se cerca de $1,0 \mathrm{ml}$ de sangue de cada animal, que foi acondicionado em tubos plásticos sem anticoagulante e centrifugado a 3.000rpm durante cinco minutos. O soro obtido foi utilizado para determinações de proteína total sérica, por meio de refratometria, e de creatinocinase $(\mathrm{CK})$, creatinocinase fração MB (CK-MB), lactato desidrogenase (LDH), aspartato aminotransferase (AST) e alanina aminotransferase (ALT), por colorimetria, utilizando kits comerciais e leitura em espectrofotômetro ${ }^{4}$, segundo Antoneli et al. (2007) e Diniz et al. (2007).

Foram realizadas análises de variância e comparações entre médias utilizando o teste Dunkan $(\mathrm{P}<0,05)$, segundo Sampaio (1998).

\section{RESULTADOS E DISCUSSÃO}

Na dose de $9 \mathrm{~g} / \mathrm{kg} \mathrm{PV}$, as diferentes frações da $M$. rigida não causaram alterações no eritrograma dos animais, apesar de o grupo que recebeu alcalóides ter apresentado valores médios mais baixos de hemoglobina $(\mathrm{P}<0,05)$ em relação aos demais grupos tratados (Tab. 1), porém sem nenhum significado clínico.

\footnotetext{
${ }^{1}$ Reagen - Quimibrás Indústrias Quimicas S.A. - Rio de Janeiro, Brasil.

${ }^{2}$ Contador de Células ABX'S-VET; ABX Diagnostics. EUA.

${ }^{3}$ Doles Reagentes e Equipamentos para Laboratórios Ltda Goiânia, Brasil.

${ }^{4}$ Cobas Mira (Classic, Roche) - EUA.
} 
Com relação ao leucograma, nos animais dos grupos que receberam alcalóides e taninos, houve diminuição $(\mathrm{P}<0,05)$ do número total de leucócitos em relação aos dos demais grupos, decorrente da diminuição do número de segmentados e linfócitos. É importante ressaltar que, assim como nos bovinos, a principal célula branca do camundongo é o linfócito, e a sua diminuição pode ocorrer devido à atividade dos hormônios adrenocorticais, nas condições de estresse (Thrall, 2007).

Os valores médios das plaquetas também foram semelhantes em todos os grupos.
Grant et al. (1991) relataram uma síndrome de falência cardíaca em ovelhas após administração intra-ruminal (fístula) de folhas de abacate (Persea americana) por mais de três dias. Esses autores descreveram que, após dois dias da administração das folhas, os exames hematológicos apresentaram leucocitose, que perdurou por 17 dias. Apesar de ser também descrita uma síndrome de falência cardíaca na intoxicação pela Mascagnia spp. (Tokarnia et al., 1994), as lesões mais prevalentes foram as degenerativas, do tipo hidrópico-vacuolar, e as ocorridas nas fibras de Purkinge. Isto não levou a um quadro de leucocitose.

Tabela 1. Valores hematológicos médios de camundongos após administração diária de $9 \mathrm{~g} / \mathrm{kg}$ (A) de diferentes frações da Mascagnia rigida: alcalóides (GIA), flavanóides (GIIA), taninos (GIIIA), saponinas (GIVA) e grupo-controle (GVA)

\begin{tabular}{lccccc}
\hline & GIA & GIIA & GIIIA & GIVA & GVA \\
\hline Hemácias $(/ \mu \mathrm{l})$ & 9.222 .000 & 9.280 .0000 & 9.394 .000 & 9.612 .000 & 9.658 .000 \\
Hemoglobina $(\mathrm{g} / \mathrm{dl})$ & $14,64 \mathrm{a}$ & $15,56 \mathrm{~b}$ & $15,86 \mathrm{~b}$ & $15,76 \mathrm{~b}$ & $15,78 \mathrm{~b}$ \\
Hematócrito $(\%)$ & 45,9 & 46,98 & 48,54 & 48,14 & 47,7 \\
VCM (fl) & 49,8 & 50,6 & 51,4 & 50,2 & 49,2 \\
HCM $(\mathrm{pg})$ & 15,9 & 16,76 & 16,92 & 16,40 & 16,32 \\
CHCM $(\mathrm{g} / \mathrm{dl})$ & 31,90 & 33,08 & 32,72 & 32,72 & 33,02 \\
Leucócitos totais $(/ \mu \mathrm{l})$ & $3.650 \mathrm{a}$ & $5.460 \mathrm{~b}$ & $3.062 \mathrm{a}$ & $4.822 \mathrm{~b}$ & $5.808 \mathrm{~b}$ \\
Segmentados $(/ \mu \mathrm{l})$ & 0.256 & 0.470 & 0.272 & 0.430 & 0.516 \\
Linfócitos $(/ \mu \mathrm{l})$ & $3.330 \mathrm{~b}$ & $4.876 \mathrm{~b}$ & $2.722 \mathrm{a}$ & $4.312 \mathrm{~b}$ & $5.166 \mathrm{~b}$ \\
Monócitos $(/ \mu \mathrm{l})$ & 0.066 & 0.114 & 0.072 & 0.080 & 0.124 \\
Plaquetas $(/ \mu \mathrm{l})$ & 421.000 & 498.800 & 393.200 & 440.400 & 487.600 \\
\hline
\end{tabular}

VCM: volume corpuscular médio; HCM: hemoglobina corpuscular média; CHCM: concentração de hemoglobina corpuscular média.

Valores seguidos por letras distintas na linha diferem entre si pelo teste Duncan $(\mathrm{P}<0,05)$.

$\mathrm{Na}$ dose de $18 \mathrm{~g} / \mathrm{kg}$, os animais que receberam a fração de taninos (GIIIB) apresentaram valores de eritrócitos, hemoglobina e volume globular menores que os do grupo-controle (Tab. 2), porém dentro dos limites de referência para a espécie, segundo Jain (1993). Melo et al. (2005), ao estudarem o hemograma de ovelhas Santa Inês após ingestão de extrato aquoso da $M$. rigida, observaram anemia normocítica normocrômica. Algumas plantas como Caparis tomentosa (Ahmed e Adam, 1979) e Brassica oleracea (Smith e Scherman, 1994) causam anemia em ruminantes. A diferença observada no eritrograma dos animais que receberam a fração de taninos foi acompanhada de valores mais baixos de proteínas plasmáticas, o que indica hemodiluição. É importante frisar que nenhum animal foi classificado como anêmico. Essas observações sugerem que muitas alterações que ocorrem nas intoxicações são resultantes de outros efeitos, tais como estado de saúde dos animais na ocasião da intoxicação, incluindo baixos valores de proteína sérica e prévia lesão hepática, as quais contribuem para $o$ aparecimento de outras alterações.

Em relação ao leucograma, de forma semelhante, os animais que receberam taninos apresentaram diminuição $(\mathrm{P}<0,05)$ do número total de leucócitos, decorrente da diminuição do número de segmentados e linfócitos. 
Tabela 2. Valores hematológicos médios de camundongos após administração diária de $18 \mathrm{~g} / \mathrm{kg}$ (B) de diferentes frações da Mascagnia rigida: alcalóides (GIB), flavanóides (GIIB), taninos (GIIIB), saponinas (GIVB) e grupo-controle (GVB)

\begin{tabular}{lccccc}
\hline & GIB & GIIB & GIIIB & GIVB & GVB \\
\hline Hemácias $(/ \mu \mathrm{l})$ & $9.998 .000 \mathrm{~b}$ & $9.408 .000 \mathrm{ab}$ & $8.697 .500 \mathrm{a}$ & $9.594 .000 \mathrm{~b}$ & $9.658 .000 \mathrm{~b}$ \\
Hemoglobina $(\mathrm{g} / \mathrm{dl})$ & $15,86 \mathrm{~b}$ & $15,74 \mathrm{~b}$ & $14,40 \mathrm{a}$ & $15,40 \mathrm{~b}$ & $15,78 \mathrm{~b}$ \\
Hematócrito $(\%)$ & $49,58 \mathrm{~b}$ & $47,78 \mathrm{~b}$ & $44,6 \mathrm{a}$ & $47,66 \mathrm{~b}$ & $47,7 \mathrm{~b}$ \\
VCM $(\mathrm{fl})$ & 49,6 & 50,8 & 51,3 & 50,0 & 49,2 \\
HCM $(\mathrm{pg})$ & 15,84 & 16,74 & 16,63 & 16,06 & 16,32 \\
CHCM $(\mathrm{g} / \mathrm{dl})$ & 31,98 & 32,92 & 32,40 & 32,72 & 33,02 \\
Leucócitos totais $(/ \mu \mathrm{l})$ & $5.680 \mathrm{~b}$ & $5.882 \mathrm{~b}$ & $3.105 \mathrm{a}$ & $5.312 \mathrm{~b}$ & $5.808 \mathrm{~b}$ \\
Segmentados $(/ \mu \mathrm{l})$ & $0.498 \mathrm{~b}$ & $0.376 \mathrm{~b}$ & $0.278 \mathrm{a}$ & $0.436 \mathrm{~b}$ & $0.516 \mathrm{~b}$ \\
Linfócitos $(/ \mu \mathrm{l})$ & $5.040 \mathrm{~b}$ & $5.378 \mathrm{~b}$ & $2.758 \mathrm{a}$ & $4.800 \mathrm{~b}$ & $5.166 \mathrm{~b}$ \\
Monócitos $(/ \mu \mathrm{l}))$ & 0.146 & 0.124 & 0.068 & 0.078 & 0.124 \\
Plaquetas $(/ \mu \mathrm{l})$ & $501.800 \mathrm{~b}$ & $469.200 \mathrm{ab}$ & $357.250 \mathrm{a}$ & $475.600 \mathrm{ab}$ & $487.600 \mathrm{ab}$ \\
\hline
\end{tabular}

VCM: volume corpuscular médio; HCM: hemoglobina corpuscular média; CHCM: concentração de hemoglobina corpuscular média.

Valores seguidos por letras distintas na linha diferem entre si pelo teste Duncan $(\mathrm{P}<0,05)$.

Alcalóides, flavanóides, taninos e saponinas na dose de $27 \mathrm{~g} / \mathrm{kg}$ também não alteraram o eritrograma de forma significativa. Entretanto, no grupo que recebeu taninos na dose de $27 \mathrm{~g} / \mathrm{kg}$, houve aumento $(\mathrm{P}<0,05)$ dos valores médios do hematócrito, e não houve aumento nos valores de eritrócitos e hemoglobina, contudo esses estavam suficientemente altos, indicando policitemia absoluta (Tab. 3). A policitemia absoluta, muitas vezes, é transitória e resultante de maior demanda de oxigênio ou de resposta ao estresse.
Nas policitemias relativas, ocorre aumento sérico da proteína total, e como isso não aconteceu, conclui-se que não houve desidratação dos animais, sendo, portanto, confirmada a policitemia absoluta secundária compensatória e não relativa. Apesar de não diferir significativamente, os animais do GIIIC apresentaram CHCM abaixo dos limites de referência para a espécie (Jain, 1993), sugestivo da presença de maior concentração de células eritróides imaturas na circulação.

Tabela 3. Valores hematológicos médios de camundongos após administração diária de $27 \mathrm{~g} / \mathrm{kg}(\mathrm{C}) \mathrm{de}$ diferentes frações da Mascagnia rigida: alcalóides (GIC), flavanóides (GIIC), taninos (GIIIC), saponinas (GIVC) e grupo-controle (GVC)

\begin{tabular}{lccccc}
\hline & GIC & GIIC & GIIIC & GIVC & GVC \\
\hline Hemácias $(/ \mu \mathrm{l})$ & 9.794 .000 & 9.527 .000 & 10.292 .000 & 9.658 .000 & 9.546 .000 \\
Hemoglobina $(\mathrm{g} / \mathrm{dl})$ & 15,84 & 15,80 & 16,14 & 15,78 & 15,28 \\
Hematócrito $(\%)$ & $49,36 \mathrm{a}$ & $47,98 \mathrm{a}$ & $52,9 \mathrm{~b}$ & $47,70 \mathrm{a}$ & $48,66 \mathrm{a}$ \\
VCM $(\mathrm{fl})$ & 50,2 & 50,5 & 51,4 & 49,2 & 51,0 \\
$\mathrm{HCM}(\mathrm{pg})$ & 16,2 & 16,65 & 15,68 & 16,32 & 16,02 \\
$\mathrm{CHCM}(\mathrm{g} / \mathrm{dl})$ & 32,08 & 32,9 & 30,46 & 33,02 & 33,02 \\
Leucócitos totais $(/ \mu \mathrm{l})$ & 5.410 & 4.435 & 5.520 & 5.462 & 5.808 \\
Segmentados $(/ \mu \mathrm{l})$ & 0,422 & 0,375 & 0,364 & 0,484 & 0,516 \\
Linfócitos $(/ \mu \mathrm{l})$ & 4.800 & 3.948 & 4.838 & 4.802 & 5.166 \\
Monócitos $(/ \mu \mathrm{l})$ & $0,188 \mathrm{ab}$ & $0,115 \mathrm{a}$ & $0,318 \mathrm{~b}$ & $0,174 \mathrm{ab}$ & $0,124 \mathrm{a}$ \\
Plaquetas $(/ \mu \mathrm{l})$ & $581.200 \mathrm{a}$ & $451.250 \mathrm{a}$ & $761.400 \mathrm{~b}$ & $510.400 \mathrm{a}$ & $487.600 \mathrm{a}$ \\
\hline
\end{tabular}

VCM: volume corpuscular médio; HCM: hemoglobina corpuscular média; CHCM: concentração de hemoglobina corpuscular média.

Valores seguidos por letras distintas na linha diferem entre si pelo teste Duncan $(\mathrm{P}<0,05)$. 
A creatina cinase $(\mathrm{CK})$ tem sido largamente usada como indicador do aumento da permeabilidade da membrana celular da fibra muscular. A atividade de CK está presente nos músculos esquelético, miocárdio e no cérebro e, em menores quantidades, no trato gastrintestinal, útero e bexiga urinária. Existem três principais formas isoenzimáticas de CK: MM (CK-MM) que é mais específica para músculo esquelético, MB (CK-MB) principalmente miocárdica, constituindo de 20 a $30 \%$ do músculo cardíaco, e BB (CK-BB) de origem cerebral (Camarozano e Henriques, 1996).

Quando ocorre necrose do miocárdio, há liberação da isoenzima CK-MB para o meio extracelular, sendo a sua dosagem um recurso importante para a detecção de lesão cardíaca (Diniz et al., 2007). Entretanto, é importante considerar os valores de $\mathrm{CK}-\mathrm{MB}$ em relação à CK total para se determinar se está realmente aumentada. Ou seja, a porcentagem de CK-MB em relação ao valor total de $\mathrm{CK}$ fornece um dado confiável quando se avalia uma possível lesão do miocárdio, pois valores aumentados de CK-MB acompanhados de aumento de CK podem ser resultantes de esforço físico, por exemplo. Porém, quando se observa aumento de CK-MB não acompanhado de aumento da $\mathrm{CK}$ total, a porcentagem dessa isoenzima fica elevada, comprovando-se lesão no músculo cardíaco.

A atividade total da lactato desidrogenase (LDH) é alta em músculos de contração rápida, porém pode modificar nas afeç̧ões hepáticas e nas anemias. Já a enzima aspartato aminotransferase (AST) está presente tanto no tecido muscular quanto no tecido hepático (Antonelli et al., 2007).

As enzimas CK, LDH e AST têm diferentes meias-vidas no plasma. Por exemplo, a CK tem meia-vida de somente poucas horas, enquanto a AST tem meia-vida muito mais longa. Como algumas enzimas também apresentam grande flutuação, na dependência da apresentação clínica ou subclínica da doença, a determinação simultânea de várias enzimas tem sensibilidade maior que a utilização de somente uma enzima (Thrall, 2007).

As frações fitoquímicas na dose $\mathrm{de} 9 \mathrm{~g} / \mathrm{kg}$ não alteraram os valores de $\mathrm{CK}$, sendo semelhantes $(\mathrm{P}>0,05)$ às do grupo-controle. Porém, ressalta-se que os grupos que receberam as frações de flavanóides (1722,2UI/l), taninos (1661,6UI/l) e saponinas (1469,75UI/l) (Tab. 4) apresentavam valores acima dos limites de referência para a espécie.

O grupo que recebeu saponinas apresentou valores médios de 977,3UI/1 da isoenzima cardíaca (MB), chegando a quase $70 \%$ em relação ao valor de CK total, seguido do grupo que recebeu a fração dos flavanóides, $61 \%$ do valor total. Não existem valores de referência para camundongos, porém, na espécie humana, estes situam-se entre 14 e $25 \%$ da CK total.

Apesar de os valores de LDH terem sido semelhantes em todos os grupos $(\mathrm{P}>0,05)$, os grupos que receberam flavanóides $(1672,8 \mathrm{UI} / 1) \mathrm{e}$ saponinas $(1001,8 \mathrm{UI} / \mathrm{l})$ apresentaram valores acima do limite para a espécie estudada (Tab. 4).

Stadler et al. (1991) relataram uma síndrome de falência cardíaca em cabras após ingestão de folhas de abacate ( $P$. americana), variedade Fuerte. Os autores determinaram as concentrações plasmáticas de CK e LDH em duas cabras intoxicadas; os valores em UI/1 foram de 640 e 12750 para CK e 655 e 5375 para LDH, respectivamente, demonstrando lesão da fibra muscular e sua magnitude.

Seriam as frações de flavanóides e saponinas presentes na $M$. rigida responsáveis pelo aumento de permeabilidade da fibra cardíaca?

A enzima AST tem origem muscular e hepática, e as frações químicas da $M$. rigida na dose de $9 \mathrm{~g} / \mathrm{kg}$ não causaram alterações significativas. A enzima ALT tem origem hepática e, da mesma forma, não apresentou alteração nos seus valores, quando comparados aos valores do grupo-controle, apesar de o grupo que recebeu saponinas apresentar valor mais baixo $(23,6 \mathrm{UI} / 1)$ quando comparado com o grupo que recebeu flavanóides $(52,7 \mathrm{UI} / \mathrm{l})$. Todos esses valores estão dentro do limite de referência para a espécie estudada, demonstrando que as frações da $M$. rigida na dose de $9 \mathrm{~g}$ não causaram lesão dos hepatócitos (Tab. 4).

A proteína sérica variou de $4,9 \mathrm{~g} / \mathrm{dl}$ no grupo que recebeu taninos a $7,7 \mathrm{~g} / \mathrm{dl}$ no grupo que recebeu flavanóides, e não houve diferença estatística entre os valores. Apesar de esses não diferirem dos valores do grupo-controle, se eles são menores que $5,0 \mathrm{~g} / \mathrm{dl}$, são considerados baixos. 
Tabela 4. Valores médios de creatina cinase (CK), isoenzima miocárdica (CK-MB), porcentagem de CK$\mathrm{MB}$, lactato desidrogenase (LDH), aspartato aminotransferase (AST), alanina aminotransferase (ALT) e proteína total (PT) de camundongos após administração diária de $9 \mathrm{~g} / \mathrm{kg}(\mathrm{A})$ de diferentes frações da Mascagnia rigida: alcalóides (GIA), flavanóides (GIIA), taninos (GIIIA), saponinas (GIVA) e grupocontrole (GVA)

\begin{tabular}{lccccc}
\hline & GIA & GIIA & GIIIA & GIVA & GVA \\
\hline CK (UI/l) & $1095,0 \mathrm{a}$ & $1722,2 \mathrm{a}$ & $1661,6 \mathrm{a}$ & $1469,75 \mathrm{a}$ & $895,3 \mathrm{a}$ \\
CK -MB (UI/l) & $436,5 \mathrm{a}$ & $778,2 \mathrm{a}$ & $346,8 \mathrm{a}$ & $977,25 \mathrm{a}$ & $227,0 \mathrm{a}$ \\
$\%$ CK-MB & $38,8 \mathrm{ab}$ & $61,0 \mathrm{bc}$ & $32,7 \mathrm{a}$ & $69,6 \mathrm{c}$ & $46,4 \mathrm{~b}$ \\
LDH (UI/l) & $799,7 \mathrm{a}$ & $1672,8 \mathrm{a}$ & $468,8 \mathrm{a}$ & $1001,8 \mathrm{a}$ & $355,0 \mathrm{a}$ \\
AST (UI/l) & $140,0 \mathrm{a}$ & $129,2 \mathrm{a}$ & $157,6 \mathrm{a}$ & $72,4 \mathrm{a}$ & $48,0 \mathrm{a}$ \\
ALT (UI/l) & $35,8 \mathrm{ab}$ & $52,8 \mathrm{a}$ & $34,6 \mathrm{ab}$ & $23,6 \mathrm{~b}$ & $43,2 \mathrm{ab}$ \\
PT (g/dl) & 7,2 & 7,7 & 4,9 & 5,7 & 5,2 \\
\hline
\end{tabular}

Valores seguidos por letras distintas na linha diferem entre si pelo teste Duncan $(\mathrm{P}<0,05)$.

Da mesma forma, as frações fitoquímicas na dose de $18 \mathrm{~g} / \mathrm{kg}$ não apresentaram diferença entre os grupos nos valores de CK quando comparados com os do grupo-controle (Tab. 5). Ou seja, duplicando-se a dose administrada, não houve diferença nem nos valores de CK total nem na fração CK-MB, mas, surpreendentemente, a maior porcentagem da fração miocárdica foi vista no grupo que recebeu alcalóides $(83,7 \%)$. Esse percentual foi significativamente maior que o observado na fração de alcalóides na dose de $9 \mathrm{~g}(38,8 \%)$ e maior que o do grupo-controle $(37,6 \%)$. Entretanto, no grupo que recebeu saponinas na dose de $18 \mathrm{~g} / \mathrm{kg}$ (GIVB), o percentual de CK-MB (71,3\%) foi semelhante ao do grupo que recebeu $9 \mathrm{~g}(69,6 \%)$, e maior $(\mathrm{P}<0,05)$ que o do grupo-controle.

Como a fração de alcalóides na dose de $18 \mathrm{~g} / \mathrm{kg}$ causou a maior liberação da enzima CK-MB (fração miocárdica), uma resposta para a questão anterior surge com uma hipótese: não só as saponinas e os flavanóides seriam necessários para causar a lesão das células musculares esqueléticas e cardíacas, mas todas as frações encontradas no estudo fitoquímico (alcalóides, flavanóides, taninos e saponinas) atuariam sinergicamente.

Para a enzima LDH, os valores foram semelhantes $(\mathrm{P}>0,05)$ entre todos os grupos (Tab. $5)$, porém todos os grupos tratados mostraram valores acima do limite normal para a espécie estudada.

A enzima AST aumentou no grupo que recebeu taninos em relação aos grupos controle e que receberam saponinas. Como não houve aumento de ALT, possivelmente o aumento de AST pode ser atribuído à maior permeabilidade de fibras musculares, já que, na dose de $18 \mathrm{~g} / \mathrm{kg}$ (GIIIB), foram observados valores de $2414,3 \mathrm{UI} / 1$ para CK e de 1004,3UI/1 para CK-MB.

O grupo que recebeu taninos na dose de $18 \mathrm{~g} / \mathrm{kg}$ apresentou valores significativamente menores para proteína total $(3,6 \mathrm{~g} / \mathrm{dl})$. É bem conhecido que os taninos condensados podem ligar-se às proteínas formando um complexo (tanino condensado-proteína) que reduz a sua degradação. Entretanto, é importante ressaltar que foi este grupo que apresentou valores mais baixos no eritrograma.

O grupo que recebeu a maior dose da fração de alcalóides $(27 \mathrm{~g} / \mathrm{kg})$ apresentou aumento significativo da isoenzima miocárdica CK-MB (1450,8UI/1) quando comparado com o grupocontrole (Tab. 6). Também, quando se comparou o grupo de $27 \mathrm{~g} / \mathrm{kg}$ com os grupos de $9 \mathrm{~g}$ $(436,5 \mathrm{UI} / 1)$ e $18 \mathrm{~g}(505,2 \mathrm{UI} / \mathrm{l})$, ficou evidente que a dose de $27 \mathrm{~g}$ foi capaz de aumentar de forma significativa os valores de CK-MB.

De forma semelhante, após a administração das frações de flavanóides e taninos na dose de $27 \mathrm{~g}$, a CK alcançou valores de 2534,5UI/1 e $2164,80 \mathrm{UI} / 1$, respectivamente. A isoenzima CKMB também estava com valores significativamente mais altos (1232,8UI/1) quando comparados com os valores do grupocontrole.

As maiores percentagens de CK-MB foram observadas nos grupos que receberam alcalóides nas doses de 18 e $27 \mathrm{~g} / \mathrm{kg}$ (84\%) (Tab. 5 e 6). 
Tabela 5. Valores médios de creatina cinase (CK), isoenzima miocárdica (CK-MB), lactato desidrogenase (LDH), aspartato aminotransferase (AST), alanina aminotransferase (ALT) e proteína total (PT) de camundongos após administração diária de $18 \mathrm{~g} / \mathrm{kg}$ (B) de diferentes frações da Mascagnia rigida: alcalóides (GIB), flavanóides (GIIB), taninos (GIIIB), saponinas (GIVB) e grupo-controle (GVB)

\begin{tabular}{lccccc}
\hline & GIB & GIIB & GIIIB & GIVB & GVB \\
\hline CK (UI/l) & 525,5 & 1025,8 & 2414,3 & 874,0 & 895,3 \\
CK -MB (UI/l) & 505,2 & 473,4 & 1004,3 & 610,8 & 227,0 \\
\% CK-MB & $83,7 \mathrm{c}$ & $55,0 \mathrm{abc}$ & $43,1 \mathrm{ab}$ & $71,3 \mathrm{bc}$ & $37,6 \mathrm{a}$ \\
LDH (UI/l) & 1861,3 & 2456,6 & 1115,8 & 1377,2 & 355,0 \\
AST (UI/l) & $122,3 \mathrm{ab}$ & $143,4 \mathrm{ab}$ & $310,0 \mathrm{~b}$ & $64,8 \mathrm{a}$ & $48,0 \mathrm{a}$ \\
ALT (UI/l) & 40,8 & 40,8 & 39,0 & 32,2 & 43,2 \\
PT (g/dl) & $6,8 \mathrm{~b}$ & $5,1 \mathrm{~b}$ & $3,6 \mathrm{a}$ & $4,2 \mathrm{~b}$ & $5,2 \mathrm{~b}$ \\
\hline
\end{tabular}

Valores seguidos por letras distintas na linha diferem entre si pelo teste Duncan $(\mathrm{P}<0,05)$.

Tabela 6. Valores médios de creatina cinase (CK), isoenzima miocárdica (CK-MB), lactato desidrogenase $(\mathrm{LDH})$, aspartato aminotransferase (AST), alanina aminotransferase (ALT) e proteína total (PT) de camundongos após administração diária de $27 \mathrm{~g} / \mathrm{kg}$ (C) de diferentes frações da Mascagnia rigida: alcalóides (GIC), flavanóides (GIIC), taninos (GIIIC), saponinas (GIVC) e grupo-controle (GVC)

\begin{tabular}{lccccc}
\hline & GIC & GIIC & GIIIC & GIVC & GVC \\
\hline CK (UI/l) & 1611,3 & 2534,5 & 2164,75 & 1333,0 & 895,25 \\
CK -MB (UI/l) & $1450,8 \mathrm{~b}$ & $764,3 \mathrm{ab}$ & $1232,8 \mathrm{~b}$ & $227,0 \mathrm{a}$ & $227,0 \mathrm{a}$ \\
\% CK-MB & $84,0 \mathrm{~b}$ & $31,6 \mathrm{a}$ & $57,3 \mathrm{ab}$ & $37,6 \mathrm{a}$ & $37,6 \mathrm{a}$ \\
LDH (UI/l) & 1012,5 & 1028,2 & 1220,0 & 746,6 & 355,0 \\
AST (UI/l) & $171,6 \mathrm{bc}$ & $230,0 \mathrm{c}$ & $174,0 \mathrm{bc}$ & $103,8 \mathrm{ab}$ & $48,0 \mathrm{a}$ \\
ALT (UI/l) & 45,8 & 50,0 & 42,0 & 36,6 & 43,2 \\
PT (g/dl) & $5,7 \mathrm{~b}$ & $4,3 \mathrm{~b}$ & $3,3 \mathrm{a}$ & $5,1 \mathrm{~b}$ & $5,2 \mathrm{~b}$ \\
\hline
\end{tabular}

Valores seguidos por letras distintas na linha diferem entre si pelo teste Ducan $(\mathrm{P}<0,05)$.

Rowe et al. (1993), ao estudarem os efeitos tóxicos da Lathyrus sylvestris em ovelhas, relataram alterações neurológicas acompanhadas de decúbito, tremores e pedalagem e um aumento sérico de CK, 60 vezes acima dos limites normais para ovinos. Uma pequena, mas severa, lesão pode induzir um aumento plasmático dos valores da atividade de CK semelhante ao obtido em uma extensa, mas suave, lesão. $\mathrm{O}$ fator que mais afeta a atividade de CK é o estresse. Em espécies como o coelho, que sofrem de estresse espontâneo, pode ocorrer aumento plasmático de CK (Lefebre et al., 1996).

Como a enzima LDH não apresentou aumento significativo após administração das frações na dose de $27 \mathrm{~g} / \mathrm{kg}$ em todos os grupos estudados, percebe-se a grande flutuação dessa enzima.

Nos animais dos grupos que receberam alcalóides (171,6UI/l), flavanóides (230,0UI/1) e taninos (174UI/l) na dose de $27 \mathrm{~g} / \mathrm{kg}$, os valores médios da enzima AST foram significativamente mais altos (Tab. 6) quando comparados com o do grupo-controle $(48,0 \mathrm{UI} / 1)$, mais uma vez suspeitando-se que esse aumento tenha origem muscular, já que a enzima ALT não sofreu alteração alguma.

Saad et al. (1970), ao estudarem os efeitos tóxicos da $M$. publiflora em cobaias, relataram valores mais elevados tanto de AST, 119,6 UI, como de ALT, 66,1UI, nos animais intoxicados quando comparados com os animais saudáveis, 26,69UI de AST e 20,01UI de ALT.

O menor valor médio de proteína total $(3,3 \mathrm{~g} / \mathrm{dl})$ foi observado no grupo que recebeu a fração de taninos na dose de $27 \mathrm{~g} / \mathrm{kg}$ (Tab.6). Esse valor, ao contrário do ocorrido no GIIC, foi acompanhado de policitemia, o que descarta a hemodiluição como causa da hipoproteinemia, e sugere que, no GIIC, os resultados alterados de eritrograma e proteínas plasmáticas podem ter ocorrido por combinação de fatores, como hemodiluição e perdas aumentadas e síntese diminuídas, tanto de 
proteínas quanto de hemácias. De qualquer modo, fica evidente que os grupos que receberam diferentes doses da fração de taninos apresentaram valores mais baixos da proteína total quando comparados com o grupo-controle, valores esses que foram diminuindo à medida que se aumentava a dose de taninos, demonstrando a influência dos taninos no metabolismo ou na absorção protéica.

Como a concentração das frações estudadas não é a mesma nas folhas verdes, além de variarem conforme a estação climática, índice pluviométrico, composição do solo, fase do desenvolvimento da planta (brotação, floração e frutificação), índice de luminosidade (Melo, 2006), outros estudos devem ser realizados na tentativa de se elucidar muitas questões.

\section{CONCLUSÕES}

As frações de $M$. rigida não foram capazes de alterar o perfil sangüíneo dos animais, e as frações de alcalóides e taninos foram capazes de causar alteração no perfil enzimático muscular, com aumento significativo da enzima miocárdica, e na porcentagem da CK-MB após a administração das frações de saponinas e taninos, demonstrando a ação tóxica da $M$. rigida sobre a fibra muscular cardíaca.

\section{REFERÊNCIAS BIBLIOGRÁFICAS}

AHMED, O.M.M.; ADAM, S.E.I. The toxicity of Jatropha curcas in sheep and goats. Res. Vet. Sci., v.27, p.89-96, 1979.

ANTONELLI, A.C.; TORRES, G.A.S.; SOARES, P.C. et al. Ammonia poisoning causes muscular but not liver damage in cattle. Arq. Bras. Med. Vet. Zootec., v.59, p.8-13, 2007.

CAMAROZANO, A.C.A.; HENRIQUES, L.M.G. Uma macromolécula capaz de alterar o resultado da CK-MB e induzir ao erro no diagnóstico do infarto agudo do miocárdio. Arq. Bras. Cardiol., v.66, p.143-147, 1996.

CUNHA, A.P.; BELLO, A.C.P.P.; LEITE, R.C. et al. Avaliação de parâmetros clínicos e hematológicos de eqüinos submetidos a um programa de controle estratégico de Amblyoma cajannensi (Fabricius, 1787). Arq. Bras. Med. Vet. Zootec., v.60, p.113-120, 2008.
DINIZ, P.P.V.P.; SCHWARTZ, D.S.; COLLICCHIO-ZUANAZE, R.C. Cardiac trauma confirmed by cardiac markers in dogs: two case reports. Arq. Bras. Med. Vet. Zootec., v.59, p.8589, 2007.

FERREIRA NETO, J.M.; VIANA, E.S.; MAGALHÃES, L.M. Patologia clínica veterinária. Belo Horizonte: Rabelo Brasil, 1978. $279 \mathrm{p}$.

GRANT, R.; BASSON, P.A.; BOOKER, H.H. et al. Cardiomyopathy caused by avocado (Persea americana Mill) leaves. J. S. Afr. Vet. Assoc., v.62, p.21-22, 1991.

GODOY, R.F.; SANTANA, A.E., CAMPOS FILHO, E. et al. Estudo eritroleucométrico e proteinograma do sangue umbilical e jugular de eqüinos ao nascimento e suas respectivas mães. Arq. Bras. Med. Vet. Zootec., v.59, p.1376-1381, 2007.

JAIN, N.C. Essentials of veterinary hematology. Philadelphia: Lea \& Febiger, 1993. 417p.

LEFEBRE, H.P.; LAROUTE, V.; BRAUN, J.P. et al. Non-invasive and quantitative evaluation of post-injection muscle damage by pharmacokinetic analysis of creatine kinase release. Vet. Res., v.27, p.343-361, 1996.

MATOS, F.J.A. Introdução a fitoquímica experimental. Fortaleza:UFC, 1988. 128p.

MEDEIROS, R.M.; NETO, S.A.; BARBOSA, R.C. et al. Sudden bovine death from Mascagnia rigida in northeastern Brazil. Vet. Hum. Toxicol., v.44, p.286-288, 2002.

MELO, M.M. Plantas que causam intoxicação aguda. Cad. Tec. Vet. Zootec., n.49, p.4-9, 2006.

MELO, M.M.; COSTA, M.E.R.; CUNHA, M.P. et al. Ovine blood profile after Mascagnia rigida intoxication. In: CONGRESO LATINOAMERICANO DE BUIATRIA, 12., 2005. Anais ... Valdivia, 2005. v.1, p.286-287.

NASCIMENTO, M.S.; HABERMEHL, G.G. Two naphto-pyrone glycosides from Mascagnia rigida. Fitoterapia, v.46, p.539-542, 1995.

PEREIRA, A.S.; SANTOS, L.F.L.; NUNESPINHEIRO, D.C.S. Alterações bioquímicas e patológicas em caprinos intoxicados por tingui (Mascagnia rigida). In: CONGRESSO PANAMERICANO DE CIENCIAS VETERINÁRIAS, 15., 1996. Anais... Campo 
Grande, 1996. v.1, p.152.

ROCHA E SILVA, M. O problema das plantas tóxicas no estado de São Paulo, Biológico, v.6, p.59-66, 1940.

ROWE, L.D.; IIE, G.W.; DELOACH, J.R. et al. The toxic effects of mature flatpea (Lathyrus sylvestris L. cv Lathvo) on sheep. Vet. Hum. Toxicol., v.35, p.127-133, 1993.

SAAD, A.D.; ANDRADE, S.O.; AGUIAR, A.A. The toxic effects of Mascagnia publiflora (Juss.) Griseb. An. Acad. Brasil. Cienc., v.42, p.235244, 1970

SAMPAIO, I.B.M. Estatística aplicada à experimentação animal. Belo Horizonte: FEPMVZ, 1998, 221p.

SMITH, M.C.; SHERMAN, D.M. Goat medicine. Philadelphia: Lea \& Febiger, 1994, $620 \mathrm{p}$.

STADLER, P.; VAN RENSBURG, I.B.J.;

NAUDÉ, T.W. Suspected avocado (Persea americana) poisoning in goats. J. S. Afr. Vet. Assoc., v.62, p.186-188, 1991.

THRALL, M.A. Hematologia e bioquímica clínica veterinária. São Paulo: Roca, 2007, 582p.

TOKARNIA， C.H.; CANELLA， C.F.C.; DÖBEREINER, J. Intoxicação por um "tingui" (Mascagnia rigida Griseb.) em bovinos no Nordeste do Brasil. Arq. Inst. Biol. Anim., v.4, p.203-215, 1961.

TOKARNIA， C.H.; DÖBEREINER， J.; PEIXOTO, P.V. Aspectos clínico-patológicos complementares da intoxicação por algumas plantas tóxicas brasileiras. Pesq. Vet. Bras., v.14, p.111-122, 1994.

VERÇOSA JÚNIOR, D.; SOUZA-FAGUNDES, E.M.; CASSALI, G.D. et al. Efeito do miriadenolídeo isolado de Alomia myriadenia (Asteraceae) sobre o tumor de Ehrlich ascítico no camundongo. Arq. Bras. Med. Vet. Zootec., v.58, p.788-798, 2006. 